\title{
Study on Innovative Experiment Model for Excellent Civil Engineer Education
}

\author{
Zhi Min Chen ${ }^{1, a^{*}}$ \\ ${ }^{1}$ School of Civil Engineering, Lanzhou Jiaotong University, Lanzhou, Gansu 730070, China \\ a chenzhimin0523@126.com
}

Keywords: Excellence initiative; Innovation platform; Innovative experiment; Management mode.

\begin{abstract}
Objective: The aim of this study was to explore a teaching model of innovative experiment for excellent civil engineer education. Methods: The study methods include questionnaire survey and analysis based on the existing experimental and innovational platforms. Results: A series of collaborative management mechanism between civil engineering Excellence Program and innovative platform was put forward. Conclusion: to achieve a win-win situation between innovative experimental ability training of excellent civil engineers and discipline development.
\end{abstract}

\section{Introduction}

The civil engineering undergraduate major of Lanzhou Jiaotong University had taken part in the batch of "Excellent Civil Engineer Education Program" or Excellence Program for short of Ministry of Education of the People's Republic of China (MOE) in 2011 [1-3] . The first Excellent Civil Engineer Class was enrolled in 2012. How to achieve the training objectives of excellent civil engineer in practice? One of the keys is to improve the students' excellence innovation experimental ability. At the same time, many innovation platforms had been established in recent years, for example, Key Laboratory of Structural Testing of Railway Ministry, Key Laboratory of Road \& Bridge and Underground Engineering of Gansu Province, Changjiang Scholars and Innovative Research Team (IRT1139) of MOE, Engineering Laboratory of Disaster Prevention in Road and Bridge Engineering of Gansu Province, etc. It is a worthy topic to discuss and to practice that how to establish a cooperative mechanism between the excellent civil engineer education and the existing innovative platforms to achieve "win-win".

\section{Analysis of the current situation and problems}

Survey of the Excellent Civil Engineer Classes. To get the key points of this research, anonymous questionnaires were designed with 17 questions [4-11] and answered by 139 students from the excellent civil engineer classes in grade 2012 and 2013. The main findings would be analyzed as follows.

Firstly, most of the students know little about the Excellence Program. The results were shown in Fig. 1.
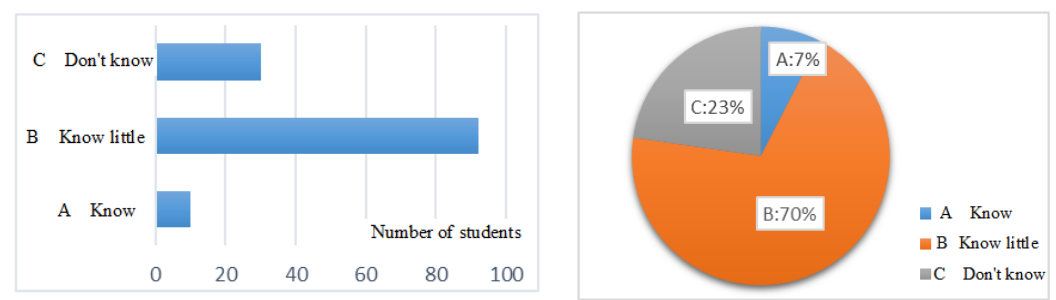

Fig. 1 Survey results of knowledge about Excellence Program

It can be seen from Fig. 1 that the students who had a comprehensive understanding about Excellence Program only accounted for $7 \%$ of the total, who had no cencept for $23 \%$ and who had some knowledge for $70 \%$. The survey results indicated a conspicuous problem that most students did not know what Excellence Program is and how to become an excellent engineer. 
Secondly, most of the students had high enthusiasm to take part in the Excellence Program. The results were shown in Fig. 2.

It can be seen from the figure that $83 \%$ of the students were interesting to take part in Excellence Program. This result illustrates most of the students were desired to become an excellence engineer. A few students have no willing to take part in Excellence Program because this were conflicts with their own willing, such as parents' expectation, further postgraduate education and so on.

Thirdly, most students wanted to improve their innovation ability and practice ability in Excellence Program. The results were shown in Fig. 3. It can be shown that the starting point of the students' willingness and Excellence Program is consistent. The students had an urgent hope to be innovative engineering talents could adapting the rapid development of Engineering and technology.

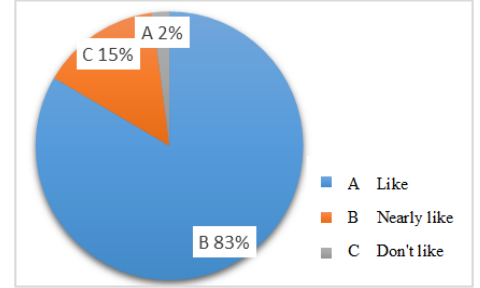

Fig. 2 Survey results of the willing to take part in Excellence Program



Fig. 3 Survey results of the abilities that excellent engineers should have

The existing experimental teaching can't meet the need of Excellence Program. Through the survey, it was found that the students in the excellent civil engineer classes have very high expectations for the innovative experimental teaching. But the existing teaching methods and teaching model is still the traditional way, it can't match the requirements of the Excellence Program and the students. The main problems were listed as follows:

There is a great gap between the teaching target of the existing innovation experiments and the requirements of the Excellence Program and the students. At the same time, the only a few students can participate in the experiments. To change this condition, it is necessary to include innovation experiment in the core curricula of the Excellence Program and to improve the innovative quality of innovation experiment.

The innovative experiment teaching content must keep pace with the times. Today, the civil engineering construction develops rapidly, it is it is necessary to make the teaching content from the engineering practice, and even directly from the experiment of scientific research project.

The existing innovative experiment teaching and management mode can't meet the requirements of civil engineering Excellence Program. On the one hand, under the current system, regardless of the topic selection, experiment content and the enthusiasm of teachers can't meet the need well to cultivate students' innovative practice ability, independent learning ability and the team cooperation ability. On the other hand, in our innovative platform, there are many scientific research projects and in-situ engineering experiments lack of experiment assistants.

Therefore, it is an urgent task to establish a new series of collaborative management mechanism between civil engineering Excellence Program and innovative platform. This kind of mechanism is also the only way to train high quality engineers with stronger ability of practice and innovation.

\section{The establishment of the new innovative experimental system of civil engineering Excellence Program}

The establishment of innovative experimental teaching management committee. Combined with graduate education mode and existing undergraduate innovative experiment management mode, a new innovative experimental teaching management committee should be established. The committee members should be selected from the laboratory teachers and successive innovation experiment teachers. The chairman should be acted by the vice president of the School of Civil Engineering. The committee should be responsible for the project review, determining of the funding lines, the coordination of laboratories and equipments, financial support, project cooperation and so on. 
Management system construction. According to the investigation, to establish a scientific and rational experimental teaching evaluation and quality assurance system and to establish an opening operation mode had became the focus of the students care about, as shown in Fig. 4.

To do this, first of all, necessary site and conditions should be provided for the excellent innovative experimental teaching projects conducted smoothly; Civil Engineering Experiment Center should be operated with opening management mode. Secondly, to ensure the teaching quality, every the excellence initiative innovation experimental base should hire an expert with a sense of responsibility as the head to provide equipment, sites and services. Thirdly, the school should allocated a certain amount of money each year as the fund of daily operations of the innovation base to ensure the students could get the capabilities of the innovative experiment by strict appraisal. This idea was also recognised by the students, the results of the survey is shown in Fig. 5. Comprehensive elements including the students' enthusiasm, practice ability and the experiment's feasibility, innovation should be acted as the evaluation elements.

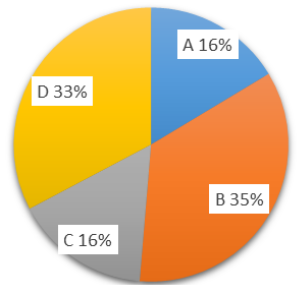

A: Two stage management system B: Scientific and rational experimental teaching evaluation and quality assurance system $\mathrm{C}$ : The lab director responsibility system D:Opening operation mode

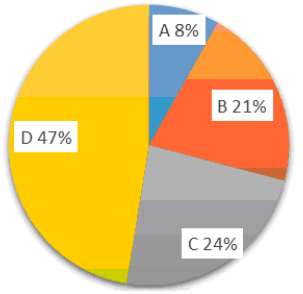

A: The students' enthusiasm B: Practice ability C: The experiment's feasibility D:Comprehensive elements above

Fig. 5 Survey results about evaluation elements

Fig. 4 Survey results about management system

Combination the experiment teaching with and scientific research and practice. To ensure the experiment subject is innovative and authentic, the experimental bases can be established and cooperating with relative scientific research projects and units or companies including engineering survey, research, design and construction. So the students can combine the theoretical knowledge with engineering practice through the innovation experiment. This kind of teaching can't be replaced by classroom teaching[12-14].

\section{Operation mechanism of innovation experiment}

To ensure the smooth implementation of excellence innovation experiment of civil engineers, operation mechanism was designed as shown in Fig. 6.

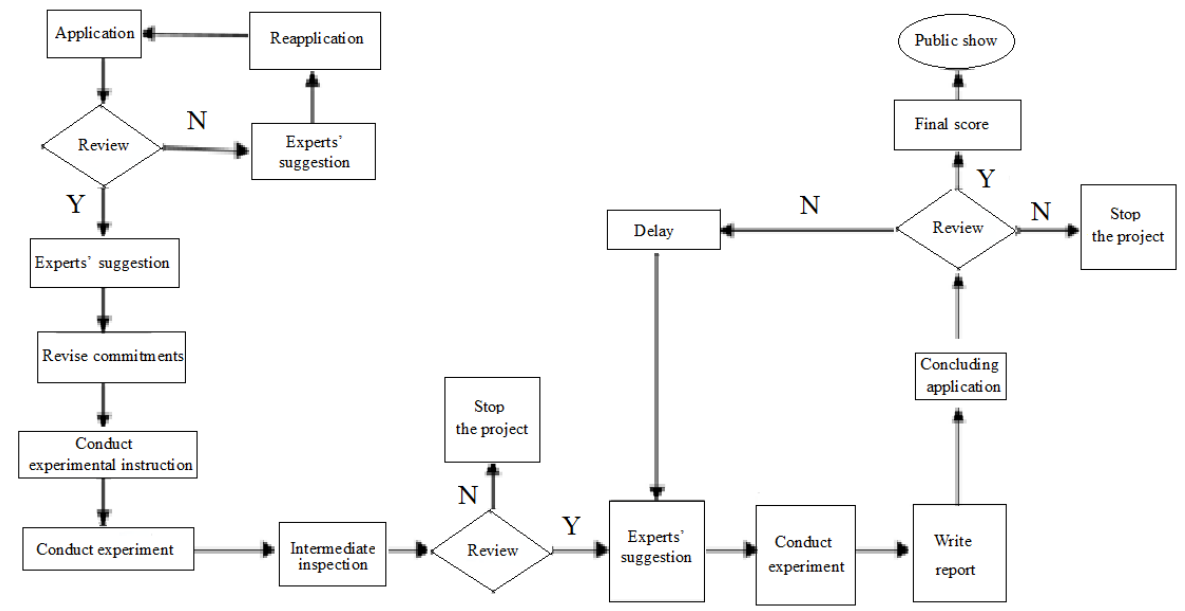

Fig. 6 Running flow chart of the project

Project application. To coincide with the cultivation of excellent civil engineers, undergraduate students in excellent civil engineer classes must apply for the innovative experiments. In principle, the 
application priority is given to sophomores and juniors. Project execution time limit should not be more than 1 year, and it must be completed before the bachelor essay design. Generally, the members can't be more than five people. The team head has overall responsibility for the innovative experimental teaching management committee. The experiment topic shoul be decided by a kind of teacher-student two-way choice mechanism.

Project review. In the first two weeks of each spring semester, students should fill out the application under teacher's guidance, including the topic, literature research, experimental scheme and so on.

The experiment project will be allowed to conduct if project review is passed.

Project operation. After the school fair show, each the project team should formulate the detail specification and arrangement schedule.

Tutors should conduct experimental instruction through team meetings at regular intervals, to discuss the progress of the experiment and the next step of experiment arrangement, research ideas, etc., to ensure the experimental results, schedule and quality.

The team should submit the intermediate inspection report to the experimental teaching management committee. The intermediate inspection report contents should include the progress of the project, the preliminary experimental situation, difficulties, the overall plan eventually determined, the next step of work plans, etc.

The intermediate inspection should be conducted with project defense. The experts should give suggestions and scores. If the intermediate inspection score of a project is not good enough, the experimental teaching management committee would give written urgency, warning or stopping. $b$

Concluding and acceptance. The research report should be the core content of supporting material. It is also the main research results of subject. The research report should be in about 3000 words and the content should include selected topic background, research contents and methods, results, innovative points, references and accessories. Accessories refer to papers, patents, award certificates, apparatus, drawings, etc.

The final score should be given by a comprehensive expert evaluation. If a project can't pass the check with reasonable written causes, the committee would allow a delay, but the delay should not exceed one year.

\section{Awards and incentive mechanism}

In order to improve the enthusiasm of teachers and students, a scientific and reasonable awards and incentive mechanism is necessary. Awards should include the first prize and second prize. The ad hoc individual awards can also be set for outstanding performance in a certain aspect of the project. Students and teachers should be awarded at the same time. In order to improve mentoring initiative, the awarded teachers should be prior in the bonus and professional title evaluation.

The award certificate and prize will be canceled if it is found that their experimental results or awards are got by plagiarism, counterfeiting, infringement of invention or by other improper means. The teachers and students would also be punished according to the school rules $[15,16]$.

\section{Summary}

According to the investigation and research, a teaching model of innovative experiment for excellent civil engineer education based on the innovation platforms was put forward. A series of policies were drawn up to ensure the equity, fair and open during the processes of topic selection, application, process management, review mechanism, publicity and so on. The main conclusions and measures are as follows:

The existing innovative experimental teaching can't adapt to the requirement of the Excellence Program.

It is necessary to include innovation experiment in the core curricula of the Excellence Program. 
Based on the existing innovation and practice platforms, the teaching model of innovative experiment for excellent civil engineer education was established.

The establishment of innovative experimental teaching management committee can ensure the project innovation, fairness and impartiality.

A scientific and reasonable awards and incentive mechanism is established to improve the enthusiasm of teachers and students.

\section{Acknowledgements}

This paper is supported by the Fundamental Research Funds of Gansu Province (214143); Building Energy Conservation and Construction Science and Technology Project of Department of Construction in Gansu Province(JK2014-15); Lanzhou Jiaotong university youth fund (2012025); Gansu province Postdoctoral Sustentation Fund (26001202); Postdoctoral Fund of Lanzhou Jiaotong University(160009).

\section{References}

[1]J. L. Chen, Q. Liang. The Research of Training Model of Excellent Engineer in Teaching University of Applied Civil Engineering, J. China Construction Education. z6(2010)

[2]H. J. Sun, Y. D. Jia. Study on innovative talents training model in the major of civil engineering Based on the "Excellent Civil Engineer Education Program", J. Education Reform and Innovation. 29(2013) 55-56.

[3]Ministry of Education of the People's Republic of China. Several Opinions about the Implementation of Education "Excellent Civil Engineer Education Program". 2011.

[4]Lanzhou Jiaotong University. Work plan of "Excellent Civil Engineer Education Program". 2011.

[5]Lanzhou Jiaotong University. Teaching Scheme of "Excellent Civil Engineer Education Program" in Civil Engineering Major. 2011.

[6]Z. J. Zhang. Study on The Cultivating Mode of Excellence Engineers in University. J. Heilongjiang Higher Education Research, 12(2010) 139-141.

[7]P. W. Song. The Ideas and Ways to Cultivate Innovation Ability of Excellent engineers. J. Talent Training, 2011.

[8]Q. C. Wei. Enhancing University-enterprise United Training, Improving The Innovation Ability of The Graduate Students in Civil Engineering Disciplines[J]. J. Research and Practice of the Construction on Civil Engineering in Higher Education Institutions, (2009)69-74.

[9]J. G. Deng, M. Wang. Study on University-enterprise Cooperation Mode of Cultivating The Innovative Ability of College Undergraduates. J. China Electric Power Education,129(2009).

[10]T.G. Dai, F. Wan. Cultivating Better Quality Students by the Process of Production, Learning and Researching Combination, J. Chinese Geology Education. 60(2006) 34-35.

[11]J. Li, C. M. Bo, X. G. Wang, G. M. Zhang. The Innovative Experimental Platform Construction for Excellence Engineers Training. Journal of EEE, 2012.

[12]J. N. Liu, J. H. Hu. Construction of Project Management Platform on Experimental Teaching Reform of University, J. Research and Exploration in Laboratory . 6(2012) 119-122.

[13]J. Qi. Study on The Cultivation of Innovative Ability of Undergraduates. Thesis of Yanshan University, 2005.

[14]X. M. Zhang. Problems and Countermeasures in Innovative Talents' Cultivation of University, J. Education and Teaching Research, 03(2011) 67-69. 
[15]K. Su, X. Xie. Exploration of Choosing Program and Implement of Innovation Experiment, J. Experiment Science and Technology, 09(2010) 67,117.

[16]Shihezi University. The Implementation and Management Measures of "the National Undergraduate Innovative Experiment Program" . 2008. 